\title{
Study on Cancer Serum Components by Fourier Transform Infrared
}

\section{Spectroscopy}

\author{
Lihui Zhao ${ }^{1, \mathrm{a}}$, Deming Han ${ }^{1, \mathrm{~b}, *}$ and Xiuping $\mathrm{Sun}^{2, \mathrm{c}, *}$ \\ ${ }^{1}$ School of Life Science and Technology, International Joint Research Center for Nanophotonics \\ and Biophotonics, Changchun University of Science and Technology, Changchun 130022, China \\ ${ }^{2}$ School of Science, Changchun University of Science and Technology, Changchun 130022, China \\ azhaolihui@yahoo.com, bhandeming2009@yahoo.com, 'sunxp@cust.edu.cn
}

Keywords: Fourier transform infrared spectroscopy, Cancer serum, Spectra

\begin{abstract}
The infrared spectra of serum from cancer patients can be measured using Fourier Transform Infrared Spectroscopy (FTIR). The changes of infrared absorption peak position in phosphor diester groups from cancer cells using OriginPro8.1 software indicates that nucleic acids contents in the cancer serum rise above normal serum levels and that the binding force between hydrogen bonds is strengthened. Calculation of the relative concentration of serum glycogen shows that glycogen concentration in cancer affected patient serum is lower than that of healthy patient serum. Infrared absorption analysis demonstrates that intermolecular hydrogen bonds between $\mathrm{C}-\mathrm{O}$ groups are largely destroyed in cancer patient serum.
\end{abstract}

\section{Introduction}

Cancer claims thousands of lives due to its irreversible damage to basic body functions in the terminal stage [1-3]. Early detection of cancerous existence is thus entailed, which may warn the doctors to take precautions against the uncontrollable growth of tumor. Macromolecular components and structures (e.g. nucleic acid, protein and sugar) in cancer cells vary from those in normal cells due to pathological changes. Metabolite discharged into blood from cancer can thus change the constituents of serum [4,5], providing guidance for subsequent assessment and treatment. Therefore, sensitive techniques must be developed to catch these variances. Among various physical detection technologies, infrared spectrum should be most suitable, overweighing nuclear magnetic resonance (NMR) and mass spectroscopy by easiness of sample preparation, sensitivity of structural changes and capability of quantification [6]. In this article, we testified the potential of Fourier Transform Infrared Spectroscopy (FTIR) [7] in early detection of cancer by testing serums from patients and normal people, suggesting FTIR is an easy, sensitive and reliable method.

\section{Experimental}

\section{Materials and Apparatus}

Cancer patient serums were obtained from clinically confirmed cancer patients and normal serum were obtained from normal people. Blood samples from patients were centrifuged for 5 minutes at $2000 \mathrm{rev} / \mathrm{min}$ without anticoagulant and the supernatant was extracted as blood serum. All samples were collected under the same conditions. 
United States thermoelectric company Nicolet360 type Fourier Transform Infrared Spectrometer was used with resolution of $4 \mathrm{~cm}^{-1}$, scanning frequency accumulation for 32 times. The scanning range started from $4000 \mathrm{~cm}^{-1}-400 \mathrm{~cm}^{-1}$, at room temperature measurement. Band area of the two ester groups $v_{\text {as }} \mathrm{PO}_{2}^{-}$to protein amide II in the nucleic acid phosphate. All detections were performed under the same conditions.

\section{Experimental Procedure}

(1) The serums are obtained from clinical patients diagnosed and normal subjects;

(2) Without anticoagulant, the venous blood of the subject is centrifuged, to save the upper serum;

(3) The infrared spectroscopy (IR) of the serums is collected in the range of $4000 \mathrm{~cm}^{-1} \sim 400 \mathrm{~cm}^{-1}$;

(4) Comparing the infrared spectral area of phosphor diester groups $v_{a s} \mathrm{PO}_{2}^{-}$in the nucleic acid to that of protein amide II;

(5) Taking the tested samples under the same conditions to the step (2);

(6) Collecting the infrared spectrum of the tested samples under the same conditions as in step (3);

(7) Comparing the infrared spectral area of $\mathrm{v}_{\mathrm{as}} \mathrm{PO}_{2}^{-}$in the step (6) to that of the amide II.

\section{Results and Discussion}

\section{Infrared Analysis of Phosphor Diester Groups}

To compare the absorption intensities of nucleic acid phosphor diester groups is an effective route since cancer is a disease caused by genetic abnormality. DNA molecules are abundant with phosphor diester groups, which have the symmetric stretching vibration $\left(v_{\mathrm{s}} \mathrm{PO}_{2}^{-}\right.$, around $\left.1079 \mathrm{~cm}^{-1}\right)$ and asymmetric stretching vibration $\left(v_{\mathrm{as}} \mathrm{PO}_{2}^{-}, 1241 \mathrm{~cm}^{-1}\right.$ around). Shown in Fig. $1, v_{\mathrm{S}} \mathrm{PO}_{2}^{-}$group is at $1079.06 \mathrm{~cm}^{-1}$ in the cancer serum, but in normal serum, the peak was shifted to a higher 1082.23 $\mathrm{cm}^{-1}$. The absorbance intensity of $\mathrm{v}_{\mathrm{s}} \mathrm{PO}_{2}^{-}$, group is higher in cancer serum, suggesting higher content of DNA. Our result is consistent with the well-known fact that cancer cell nucleiare biggeras a consequence of abnormal replication of DNA. $v_{a s} \mathrm{PO}_{2}^{-}$functional group asymmetric stretching vibration is located in $1243.01 \mathrm{~cm}^{-1}$ in cancer serum, but it is located in $1240.15 \mathrm{~cm}^{-1}$ in normal serum. The peak in cancer serum shifted by nearly $3 \mathrm{~cm}^{-1}$ and its intensity is increased. This change is due to the $\mathrm{PO}_{2}^{-}$functional groups form hydrogen bonds. So, FTIR can be used for the diagnosis of cancer.

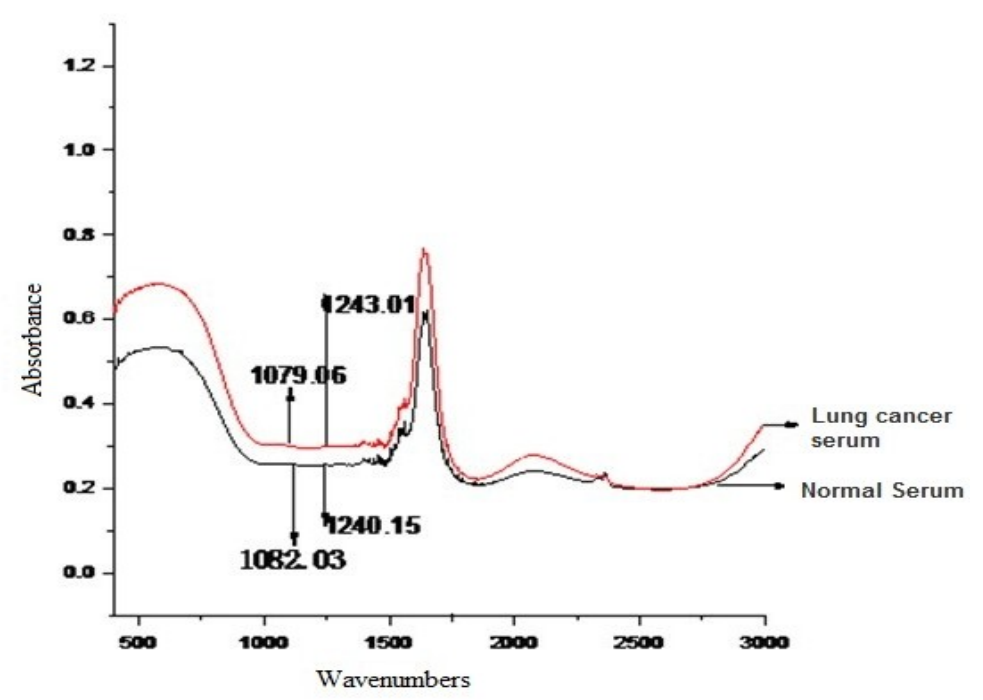

Fig. 1 Infrared spectra for $v_{\mathrm{s}} \mathrm{PO}_{2}^{-}$and $v_{\mathrm{as}} \mathrm{PO}_{2}^{-}$ 


\section{Infrared Analysis of the Glycogen C-O Groups}

Infrared spectral peak of $\mathrm{C}-\mathrm{O}$ groups of the glycogen in the cancer serum compared to the normal serum was obviously lower. Vibration of the $\mathrm{C}-\mathrm{O}$ groups generally appears in about $1023 \mathrm{~cm}^{-1}$. Here we use ratio of absorbance between the $\mathrm{C}-\mathrm{O}$ groups and neighboring $\mathrm{v}_{\mathrm{as}} \mathrm{PO}_{2}^{-}$, groups to reflect the relative content of glycogen in cells.

\section{Infrared Analysis of the Protein C-O Groups}

Fig. 2 shows the infrared spectral peak in $1165 \mathrm{~cm}^{-1}$, formed by the vibration of the $\mathrm{C}-\mathrm{O}$ groups of the protein amino acid, is higher in cancer serum than normal serum. $\mathrm{C}-\mathrm{O}$ groups within the protein molecules move to the higher wave number. It can be inferred that the chemical bonds of $\mathrm{C}-\mathrm{O}$ groups changed, and a new group was formed. The bands above $1165 \mathrm{~cm}^{-1}$ are $\mathrm{C}-\mathrm{OH}$ bands, so it is likely that there is a new formation of functional groups $\mathrm{C}-\mathrm{OH}$. This chemical bond change may be due to energy absorbed by the $\mathrm{C}-\mathrm{O}$ groups.

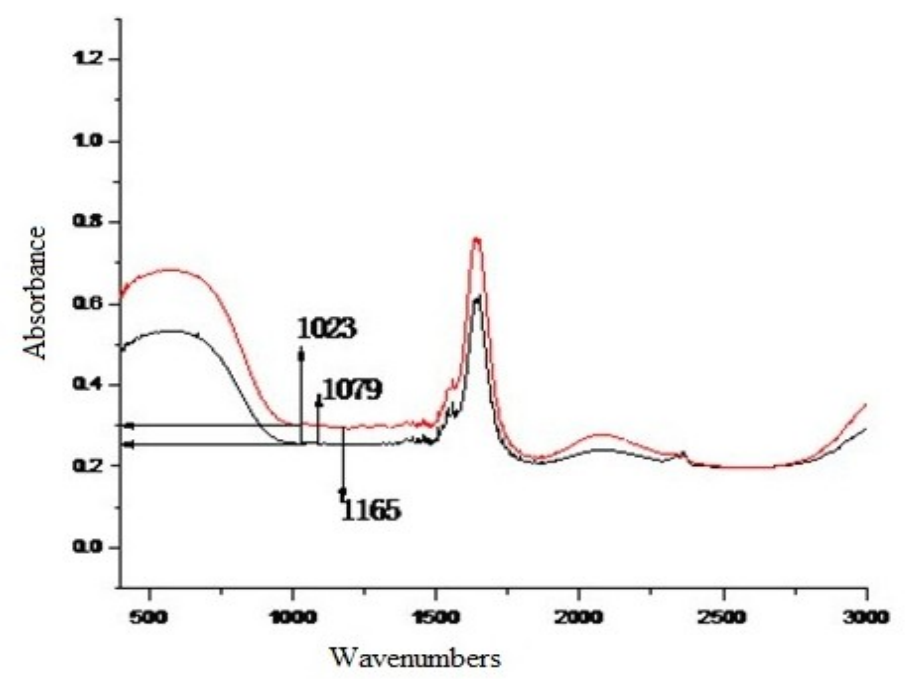

Fig. 2 Spectra of glycogen and protein $\mathrm{C}-\mathrm{O}$ groups in lung cancer serum and normal serum

\section{Analysis of Protein Secondary Structure}

Curve fitting was done with cancer serum sample and normal serum samples. The relative content of protein secondary structure was derived from the surface integral calculation. After curve fitting, the average values of protein secondary structures are shown in Table 1 as follows:

The average of content of protein secondary structure as intermolecular $\beta$-sheet, corner and curl in cancer serum is higher in cancer serum comparing to protein in normal serum; however $\alpha$-helix and total helix is decreased in cancer serum. The ratio of intermolecular $\beta$-sheet and intramolecular $\beta$-sheet of protein molecules can be used to measure the metabolic status of the cells in the cancer serum. The higher ratio in cancer serum shows that cell metabolism in the cancer serum is more vigorous than normal serum. In cancer cells, the enzyme activity is enhanced, resulting in the fast proliferation of cell. This is consistent with the data we obtained. The change of a typical helix is not obvious. 
Table 1. The average values of the protein secondary structures

\begin{tabular}{lll}
\hline Structure & Normal & Cancer \\
\hline Intermolecular $\beta$-sheet & 20.6 & 23.5 \\
Intramolecular $\beta$-sheet & 17.5 & 9.3 \\
$\alpha$-helix & 23.0 & 18.0 \\
Atypical spiral & 16.2 & 14.6 \\
Corner & 7.1 & 23.8 \\
Curl & 14.4 & 11.8 \\
Total $\beta$-sheet & 38.2 & 33.1 \\
The total spiral & 39.4 & 32.3 \\
\hline
\end{tabular}

\section{Conclusions}

The components of lung cancer and normal human serum have been investigated using Fourier Transform Infrared Spectroscopy. Some conclusions can be drawn as follows: (1) The absorbance of the $v_{\mathrm{s}} \mathrm{PO}_{2}^{-}$functional groups of nucleic acids significantly increases for lung cancer serum, and the peaks move to higher wave number. This indicates that the contents of nucleic acids DNA increase, and $v_{\mathrm{as}} \mathrm{PO}_{2}^{-}$groups form a hydrogen bond. (2) The relative content of glycogen in the lung cancer serum decreases in contrast to that of normal human. (3) $\mathrm{C}-\mathrm{O}$ groups of protein in cancer serum moving to the higher wave number, it may be due to the destruction of intermolecular hydrogen bonds in the cancer serum. From the above analysis, it can be seen that the differences in peaks between the cancer serum and normal serum can be used to diagnose cancer.

\section{Acknowledgments}

The authors are grateful to the financial aid from the Program of Science and Technology Development Plan of Jilin Province (Grant No. 20110438) and the Funds for Doctoral Scientific Research Startup of Changchun University of Science and Technology (Grant No. 40301855).

\section{References}

[1] R. Kontek and H. Nowicka: Drug Chem. Toxicol. Vol. 36 (2013), p. 335

[2] D. Ziech, I. Anestopoulos, R. Hanafi, G.P. Voulgaridou, R. Franco, A.G. Georgakilas, A. Pappa, and M.I. Panayiotidis: Cancer Lett. Vol. 327 (2012), p. 16

[3] D. Anastassiou, V. Rumjantseva, W.Y. Cheng, J.Z. Huang, P.D. Canoll, D.J. Yamashiro and J.J. Kandel: BMC Cancer Vol. 11 (2011) p. 529

[4] D.R. Chen, S.T. Chen, T.W. Wang, C.H. Tsai, H.H. Wei, G.J. Chen, T.C. Yang, C. Lin and P.H. Lin: Toxicol. Lett. Vol. 202 (2011), p. 244

[5] P.G. Lokhov, M.I. Dashtiev, S.A. Moshkovskii and A.I. Archakov: Metabolomics Vol. 6 (2010), p. 156

[6] I. Sedenkova, M. Trchova, J. Stejskal and J. Bok: Appl. Spectrosc. Vol. 61 (2007), p. 1153

[7] S. Rehman, Z. Movasaghi, J.A. Darr and I.U. Rehman: Appl. Spectrosc. Rev. Vol. 45 (2010), p. 355 